\title{
A PERCEPÇÃO DOS PRONOMES DE SEGUNDA PESSOA DO SINGULAR EM CONSTRUÇÕES CAUSATIVAS: UM ESTUDO EXPERIMENTAL
}

\author{
THE PERCEPTION OF SECOND PERSON SINGULAR \\ PRONOUNS IN CAUSATIVE CONSTRUCTIONS: AN \\ EXPERIMENTAL STUDY
}

Thiago Laurentino de Oliveira"

Lucas Guimarães de Araujo**

Resumo: Neste trabalho, reportamos os resultados preliminares de uma pesquisa sobre a variação entre os pronomes de segunda pessoa do singular te e você em construções causativas. Nossos objetivos eram testar se essas estruturas são um ambiente favorecedor da variante você e se a agentividade do predicado do evento causado também atua como um fator condicionador dessa variante. Para tanto, utilizamos a metodologia experimental e construímos uma tarefa de escolha induzida, que foi aplicada a 78 falantes do português brasileiro. Os resultados experimentais apontaram que os participantes escolheram significativamente mais as frases experimentais que continham o pronome você do que as que continham o pronome te, sobretudo quando o predicado do evento causado apresentava verbos semanticamente mais agentivos.

Palavras-chave: pronomes pessoais; construções causativas; segunda pessoa do singular.

Aвstract: In this paper, we report the preliminary results of a research on the variation between the second person singular pronouns te and você in causative constructions. Our goals were to test whether these structures are a favorable environment for você and whether the agentivity of the caused event also acts as a conditioning factor for this variant. For that, we used the experimental methodology and built a

\footnotetext{
"Doutor em Letras Vernáculas (Língua Portuguesa) pela Universidade Federal do Rio de Janeiro (UFRJ). Professor Adjunto do Departamento de Letras Vernáculas (Setor de Língua Portuguesa) da Faculdade de Letras da UFRJ. Docente permanente do Programa de Pós-Graduação em Linguística da UFRJ. E-mail: thiagolaurentino@letras.ufrj.br.

${ }^{\text {"th }}$ Licenciando em Letras (Português e Literaturas de Língua Portuguesa) da Faculdade de Letras da Universidade Federal do Rio de Janeiro (UFRJ). Atuou como pesquisador de Iniciação Científica (sem bolsa) nos anos de 2019 e 2020, sob a orientação do professor Thiago Laurentino de Oliveira. E-mail: lucasguimaraes@letras.ufrj.br.
} 
forced-choice task, which was applied to 78 Brazilian Portuguese speakers. The experimental results showed that participants chose significantly more experimental sentences that contained você than those that contained te, especially when the caused event had more semantically agentive verbs.

KEYwORDs: personal pronouns; causative constructions; second person singular.

\section{CoNSIDERAÇõES INICIAIS}

Neste artigo, apresentamos os resultados preliminares de um experimento de escolha induzida, por meio do qual buscamos analisar a influência de fatores estruturais e semânticos sobre a variação pronominal de segunda pessoa do singular (doravante, 2SG) na função sintática de objeto direto (doravante, OD). Especificamente, investigamos, no referido experimento, a escolha das variantes te e você inseridas em construções causativas, como as exemplificadas em (01):

(01)

a. Maria te fez limpar o quarto.

b. Maria fez você limpar o quarto.

Os estudos acerca da expressão pronominal de 2SG têm apontado que a difusão da forma você como pronome pessoal no português brasileiro (PB) não ocorre no mesmo ritmo em todos os contextos morfossintáticos da oração. Dados diacrônicos apontam para um aumento, principalmente ao longo do século XX, na frequência de uso de você na posição de sujeito (cf. RUMEU, 2008; MACHADO, 2011; SOUZA, 2012). Em contrapartida, o cenário de implementação em outras funções sintáticas é bastante distinto; em relação à função de objeto direto, especificamente, os dados diacrônicos revelam o predomínio da forma átona te, que registra alta frequência de uso (cf. SOUZA, 2014).

Diante dessa questão, os estudos mais recentes (cf. PIMIENTA, 2013; SCHWENTER et al., 2018) têm buscado rastrear fatores que condicionam/favorecem a utilização de você em outras funções sintáticas para além do sujeito, como é o caso do objeto direto. Para tanto, além da análise de corpora linguísticos, esses pesquisadores adotam também a metodologia experimental, a fim de observar como os falantes do PB percebem/avaliam a forma você em função de objeto direto. Afiliando-nos a essa perspectiva de investigação, estabelecemos, neste trabalho, dois objetivos: examinar os padrões de escolha pronominal dos falantes do Rio de Janeiro expostos a enunciados com os pronomes te e você em construções causativas e analisar se fatores relacionados a esse tipo de enunciado influenciam os falantes na escolha das variantes de OD de 2 SG. 
Estruturamos este artigo em seis seções: após estas considerações iniciais, revisitamos, na segunda seção, algumas pesquisas que exploraram, direta ou indiretamente, a variação entre te e você, a partir de dados de corpora do $\mathrm{PB}$, tanto em perspectiva diacrônica quanto em perspectiva sincrônica; na terceira seção, apresentamos uma caracterização teórica das chamadas construções causativas, que estão no foco do experimento aplicado; expomos o desenho experimental da tarefa de escolha induzida elaborada para analisar a variação do OD de 2 SG em construções causativas na quarta seção. Reportamos, na penúltima seção, os resultados preliminares obtidos a partir do experimento, discutindo-os à luz das hipóteses destacadas para esta pesquisa. Por fim, pontuamos, na última seção, as contribuições mais relevantes desta análise, além de sinalizarmos os próximos passos da pesquisa.

\section{A VARIAÇÃO TE/VOCÊ NO PB}

O quadro de variação linguística na representação da 2SG, identificado no contexto morfossintático de acusativo ou objeto direto (OD), está diretamente relacionado ao processo de reconfiguração do sistema pronominal do português, sobretudo na variedade brasileira. Através da gramaticalização da antiga forma de tratamento Vossa Mercê, o sistema pronominal do português passa a contar com uma nova estratégia de referência ao interlocutor: a forma você (cf. LOPES; DUARTE, 2003; LOPES; CAVALCANTE, 2011). Essa forma, principalmente a partir do final do século XIX, vai perdendo seu traço pragmático de cortesia/formalidade e tem seu uso estendido para o âmbito da intimidade, no qual, anteriormente, havia apenas o pronome tu, advindo da língua latina (CINTRA, 1972; FARACO, 1996).

Uma vez que a forma tu continua a ser utilizada, agora ao lado da forma inovadora você, instaura-se, na posição morfossintática de sujeito da oração, um caso de variação pronominal na referência à 2SG, no plano da intimidade/proximidade. De acordo com Lopes et al. (2018, p. 145), essa mudança “[...] traz consequências importantes para o restante do paradigma pronominal, principalmente para as tradicionalmente chamadas formas oblíquas átonas e tônicas e formas possessivas". Os autores sinalizam ainda que, da coexistência entre as formas pronominais relacionadas aos paradigmas de tu (te, ti, teu, contigo) e de você (o/a, lhe, seu, você), emerge, no $\mathrm{PB}$, um paradigma supletivo, que combina formas antes vinculadas apenas a tu ou a você. Esse "sincretismo" de formas pronominais, entretanto, não corresponde a uma frequência de uso equilibrada entre as variantes, como os mesmos autores destacam:

[...] você entra efetivamente como uma nova forma de referência à segunda pessoa apenas na função de sujeito. Nas outras relações gramaticais, esse pronome não apresenta o mesmo ritmo de implementação, principalmente como complemento verbal. Nesse contexto [...], o clítico te sempre foi bem produtivo, combinando-se com o pronome sujeito você desde o século XVIII, pelo menos (LOPES et al., 2018, p. 148). 
No que diz respeito às formas pronominais focalizadas neste artigo, podemos perceber, então, que a variação entre te e você é decorrente da emergência do paradigma supletivo descrito por Lopes et al. (2018). Essa variação se verifica no contexto morfossintático de OD, devido à possibilidade de você ser utilizado nessa posição da sentença. $\mathrm{O}$ mesmo quadro não se verifica na posição de sujeito, haja vista a impossibilidade de a variante te ocupar a posição de sujeito no português. Os exemplos em (02) ilustram esses aspectos:

a. Eu te encontrei / encontrei você no mercado.

b. *Te encontrou o João / Você encontrou o João no mercado.

Antes de tratarmos especificamente da variação entre te e você no contexto delimitado para a nossa investigação, isto é, no interior das construções causativas, é importante revisar brevemente algumas pesquisas que analisaram essa variação em um plano mais amplo. Nas subseções que seguem, destacaremos trabalhos que trataram do tema tanto na perspectiva diacrônica quanto na perspectiva sincrônica atual.

\section{A VARIAÇÃo TE/VOCÊ EM ESTUDOS DIACRÔNICOS}

A primeira investigação que destacamos é a tese de doutorado de Machado (2011). Com base em uma amostra de peças teatrais brasileiras e portuguesas, a pesquisadora analisa a variação nas formas de tratamento ao interlocutor e as mudanças ocorridas no sistema pronominal de ambas as variedades, entre os séculos XIX e XX. O foco da tese de Machado (2011) são as formas variantes na posição de sujeito, mas as ocorrências dos pronomes de 2SG na posição de objeto direto também foram controladas. $\mathrm{Na}$ amostra analisada, quatorze peças eram representativas do PB, ambientadas no Rio de Janeiro. Na tabela 1 , reunimos os dados que Machado (2011) coletou, referentes à posição de complemento verbal:

Tabela 1 - Distribuição das formas pronominais de 2SG em posição de complemento verbal em peças teatrais brasileiras dos séculos XIX e XX

\begin{tabular}{c|c|c|c|c|c|c|c|c|c}
\hline Variante & te & ti & o/a & lhe & se/si & você & Prep.+você & vos & total \\
\hline Oco. & 328 & 34 & 127 & 297 & 115 & 21 & 120 & 10 & \multirow{2}{*}{1052} \\
\hline$\%$ & $31 \%$ & $3 \%$ & $12 \%$ & $28 \%$ & $11 \%$ & $2 \%$ & $12 \%$ & $1 \%$ & \\
\hline
\end{tabular}

Fonte: Machado (2011, p. 152)

O resultado da autora mostra que a variante te foi a mais frequente, correspondendo a 31\% das ocorrências totais para a posição de complemento. Outras variantes clíticas com referência à 2 SG também foram encontradas, como the (28\%) e o/a (12\%). Nesse cômputo geral, a variante você ocupa a penúltima posição, correspondendo a $2 \%$ das ocorrências e ficando 
na frente apenas do clítico vos. Se distribuirmos as ocorrências das variantes na diacronia, encontramos os seguintes percentuais:

Tabela 2-Ocorrência das variantes te e você em posição de complemento verbal ao longo do tempo nas peças teatrais brasileiras

\begin{tabular}{c|c|c|c}
\hline & te & você & total \\
\hline $\mathbf{X I X} / \mathbf{2}$ & $\begin{array}{c}141 / 335 \\
42 \%\end{array}$ & $\begin{array}{c}03 / 335 \\
1 \%\end{array}$ & 335 \\
\hline $\mathbf{X X} / \mathbf{1}$ & $\begin{array}{c}75 / 332 \\
23 \%\end{array}$ & $\begin{array}{c}02 / 332 \\
1 \%\end{array}$ & 332 \\
\hline $\mathbf{X X} / \mathbf{2}$ & $\begin{array}{c}51 / 280 \\
18 \%\end{array}$ & $\begin{array}{c}10 / 280 \\
4 \%\end{array}$ & 280 \\
\hline
\end{tabular}

Fonte: Machado (2011, p. 152) ${ }^{1}$

Na tabela 2, observamos uma certa diminuição nos percentuais da variante te ao longo do tempo, que reduz de $42 \%(\mathrm{XIX} / 2)$ para $18 \%(\mathrm{XX} / 2)$. Não podemos atribuir, porém, essa diminuição a um aumento de frequência da variante você: como se vê, embora o número de ocorrências dessa forma tenha subido (de $1 \%$ para $4 \%$ ), o índice registrado não supera nem alcança o percentual de te em XX/2. ${ }^{2}$ Diante de tal resultado, Machado (2011, p. 224) comenta que

o alçamento de vocề à posição de principal e, em alguns momentos, única estratégia pronominal de referência à segunda pessoa do discurso gera um aumento nos índices de usos dos pronomes oblíquos e possessivos de $3^{a}$ pessoa. Todavia, mesmo com o "desaparecimento" em algumas décadas do século XX, de tu na função de sujeito, observa-se a permanência, principalmente, do pronome oblíquo átono te [...]. Tal fato ilustra a conservação das formas de P2 e a possível associação destas a você para a designação de um mesmo interlocutor por um determinado falante.

Ainda que não tenha realizado uma análise quantitativa mais detalhada das formas de 2SG utilizadas na posição de complemento verbal, Machado (2011, p. 151) afirma que os "[...] resultados permitem inferir que um mesmo interlocutor pode ter sido tratado, ao mesmo tempo [...] por você e uma forma pronominal de $2^{\mathrm{a}}$ pessoa como te”. Essa análise sugere, pois,

\footnotetext{
${ }^{1}$ A autora subdivide os dados segundo o ano de publicação das peças. Desse modo, os dados da segunda metade do século XIX correspondem a peças de 1857, 1870 e 1896; os da primeira metade do século XX, a peças de 1908, 1918 e 1937; os da segunda metade do século XX, a peças de 1952, 1962, 1972, 1980 e 1995. Vale ressaltar que os valores totais reproduzidos correspondem ao total de cada período, incluindo as outras variantes controladas por Machado (2011), mas que não foram inseridas na tabela porque não estão no foco da nossa discussão.

${ }^{2}$ Em sua análise, Machado (2011) atribui a diminuição nos índices de te ao aumento na frequência de uso de outras variantes, principalmente a variante lhe, que parece competir mais diretamente com te, sobretudo nos dados extraídos das peças da primeira metade do século XX.
} 
que o contexto morfossintático de OD parece desfavorecer o uso da variante você, tendo em vista a permanência de te.

Outro estudo sobre o tema a ser mencionado, também na perspectiva diacrônica, é a dissertação de Souza (2014). A pesquisadora mapeia as variantes de 2SG na posição de OD a partir de uma amostra de cartas pessoais escritas entre as décadas de 1880 e 1980. Tendo obtido um total de 433 dados, Souza (2014) contabiliza 337 ocorrências de te (78\%), 40 de o/a (9\%), 29 de você (7\%) e 17 de lhe (4\%), além de 10 ocorrências de objeto nulo (2\%). Os resultados da autora evidenciam uma preferência pela forma te, bastante associada à variedade carioca (e à região sudeste), já que os autores das cartas eram do Rio de Janeiro. Na figura 1, temos a distribuição desses dados segundo a diacronia analisada:

Figura 1 - Distribuição das formas acusativas de 2SG ao longo de um século na escrita epistolar carioca

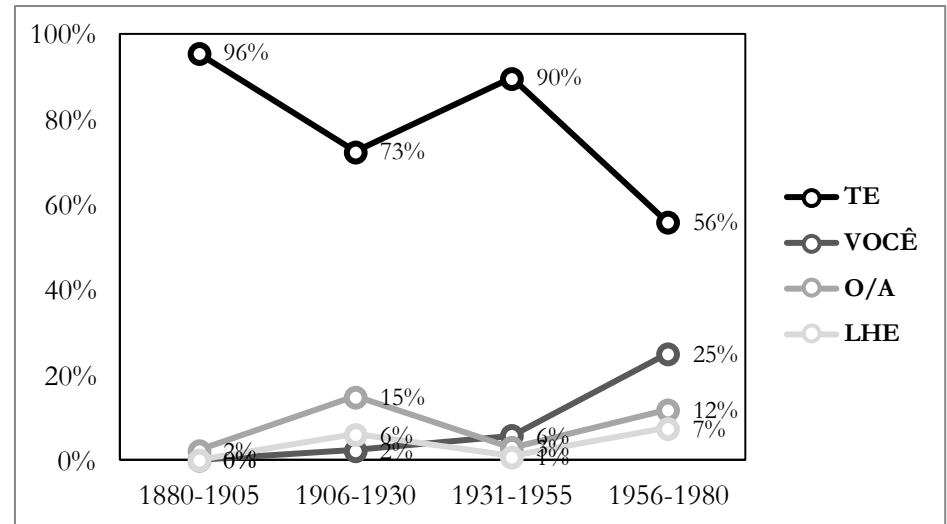

Fonte: elaboração própria, com base nos dados quantitativos de Souza (2014, p. 110)

Como revelam as linhas do gráfico, a variante te registra uma frequência superior a $50 \%$, em todos os recortes temporais da amostra, o que vai ao encontro do que afirma Machado (2011) e Lopes et al. (2018) sobre a preservação de te no sistema pronominal do PB. Percebemos, porém, que, diferentemente dos dados extraídos das peças teatrais, nas cartas, o aumento da variante você ao longo do tempo é mais expressivo: nenhum dado na fase de 1880-1905, 2\% em 1906-1930, 6\% em 1931-1955 e 25\% em 1956-1980. Essa forma é, inclusive, nas duas últimas fases, a segunda variante mais frequente, atrás apenas dos percentuais de te. Apesar desse quadro, os dados diacrônicos de Souza (2014) não contrariam a análise de Machado (2011), visto que te foi, também nas cartas pessoais, a variante majoritária, o que sugere o forte favorecimento desse pronome na posição de $\mathrm{OD}$, em detrimento da variante você.

Nos parágrafos seguintes, trazemos alguns achados de pesquisas que analisam esse fenômeno de variação em perspectiva sincrônica. 


\section{A VARIAÇÃo TE/VOCÊ EM ESTUDOS SINCRÔNICOS}

Os estudos de Pimienta (2013) e de Schwenter et al. (2018), que revisaremos nesta subseção, compartilham entre si dois aspectos importantes para a nossa discussão: analisam mais diretamente as variantes te e você no contexto de acusativo e exploram a percepção sociolinguística dos falantes do PB. Pimienta (2013) investiga, em sua dissertação, as formas variantes de 2 SG na variedade do Rio de Janeiro. A autora coletou dados a partir de entrevistas sociolinguísticas, conversas em uma mídia social e de testes de atitude. No tratamento dos dados, Pimienta (2013) subdivide as ocorrências segundo a predicação da oração em que ocorria o pronome em simples (um único núcleo verbal) ou complexa (mais de um núcleo verbal). A tabela 3 apresenta os dados obtidos:

Tabela 3 - Ocorrências das variantes te e você em entrevistas e conversas espontâneas

\begin{tabular}{c|c|c|c}
\hline Tipo de oração & te & você & total \\
\hline Simples & $\begin{array}{c}109 / 135 \\
81 \%\end{array}$ & $\begin{array}{c}16 / 135 \\
12 \%\end{array}$ & 135 \\
\hline Complexas & $8 / 20$ & $9 / 20$ & 20 \\
\hline
\end{tabular}

Fonte: elaboração própria, com base nos dados quantitativos de Pimienta $(2013$, p. 86,99$)$

Em termos gerais, os dados de objeto direto de 2SG foram mais frequentes no contexto de oração simples do que no de oração complexa. Dentre as orações simples, vemos que te foi a variante predominante, correspondendo a $81 \%$ das ocorrências. Em segundo lugar, com uma frequência bem menor, aparece a variante você, com $12 \% .{ }^{3}$ Já entre as orações complexas, os índices das variantes são praticamente iguais: $40 \%$ para te ( 8 ocorrências) e $45 \%$ para você (9 ocorrências). ${ }^{4}$ Pimienta (2013) afirma que essa diferença nas frequências quanto ao tipo de oração se deve ao fato de que, em certos ambientes sintáticos de articulação de orações, o OD da oração matriz funciona como sujeito da sentença subordinada. Essa especificidade bloquearia a ocorrência de te, já que ele não pode funcionar como sujeito (conforme já mostramos no início da seção).

Com o objetivo de verificar se a baixa frequência de uso da variante você como OD estaria relacionada a uma rejeição ou estigma por parte dos falantes, Pimienta (2013) aplicou também um teste de atitude linguística a falantes nativos do Rio de Janeiro. Os participantes foram expostos a sentenças que traziam um OD de $2 \mathrm{SG}$ em uma oração simples. Nessas sentenças, a pesquisadora inseriu as variantes te, você e tu. Os resultados mostraram que os falantes avaliam as formas te e você de modo semelhante, com elevado grau de aceitação. Tal resultado nos leva

\footnotetext{
${ }^{3}$ A autora computou também dados de objeto nulo (4\% - 6/135), de tu (2\% - 3/135) e da forma senhor (1\% - $\left.1 / 135\right)$. ${ }^{4}$ Completam os 20 dados, duas ocorrências de senhor e uma da forma tu.
} 
a descartar a hipótese de que a variante você seja menos frequente nos dados de uso porque desperta julgamentos negativos entre os falantes.

Schwenter et al. (2018) reportam, em seu artigo, os resultados de um experimento aplicado a falantes do PB de várias cidades. O experimento proposto consistia em um julgamento de escolha induzida, no qual, através de um formulário eletrônico, os participantes tinham de indicar, dentre as opções apresentadas, a que trazia a frase mais próxima do que eles acreditavam que usariam normalmente. Nessa pesquisa, os autores focalizam especificamente as variantes te e você na posição de complemento direto e objetivam verificar se fatores discursivo-pragmáticos influenciam a variação entre as formas pronominais consideradas. Dentre os achados dessa pesquisa, destacamos o resultado encontrado para a variável "tipo de contexto", segundo a qual os autores postulam que os falantes preferem a variante você em contextos contrastivos. Nos contextos não contrastivos, a preferência seria pela variante te. Em (03) e (04), reproduzimos algumas frases utilizadas no experimento, em que há a diferença quanto ao tipo de contexto:

(03) Não contrastivo:

a. Eu estava te escutando.

b. Eu estava escutando você.

(04) Contrastivo:

a. Eu vi a Luana, mas queria te ver.

b. Eu vi a Luana, mas queria ver você.

Os resultados obtidos acerca dessa variável sustentam a hipótese dos autores: nas frases sem o contexto de contraste, a variante te foi escolhida pelos participantes em $76 \%$ das respostas, frente a $24 \%$ de escolha da variante você; esses índices se alteram significativamente no âmbito das frases com contexto contrastivo, em que os participantes escolheram você em $52 \%$ das respostas, contra $48 \%$ de escolha de te. Diante desse quadro, os pesquisadores comentam que

[...] contrariando muitas descrições gramaticais [...], te e você não variam 'livremente' ou 'indistintamente', mas são sensíveis a uma clara motivação discursivo-pragmática, segundo a qual vocêe a forma preferida em contextos contrastivos para muitos falantes [...]. (SCHWENTER et al., 2018, p. 284-285).

Nesse mesmo artigo, os pesquisadores postulam que a configuração morfossintática da sentença em que ocorre o OD de 2SG também influencia o uso/a escolha das variantes em foco. Mais especificamente, eles se referem às construções de sujeito acusativo, "nas quais te/você funciona ao mesmo tempo como o OD do primeiro verbo e o sujeito do verbo seguinte, que pode aparecer tanto na sua forma infinitiva [...] quanto na forma progressiva [...]". (SCHWENTER et al., 2018, p. 280). Para esse contexto morfossintático, os pesquisadores afirmam que "o 
uso de pronomes-sujeito ou pronomes retos tais como eu, você, ele/ela etc., é mais comum nessa construção no PB coloquial" (SCHWENTER et al., 2018, p. 280).

A fim de testar empiricamente essa hipótese, Schwenter et al. (2018) examinam, a partir do Corpus do Português, a frequência de uso de te e você nessas construções. Dentre as ocorrências em que o verbo da oração subordinada assumia a forma infinitiva, os autores verificaram uma distribuição bastante equilibrada, com uma pequena vantagem para a variante te $(50,2 \%, 7.247$ de 14.430 dados). Já quando o verbo da subordinada ocorria na forma progressiva (gerúndio), era a variante você a mais frequente (67,7\%, 1.091 de 1.611 dados). Eles salientam, contudo, que os índices de ocorrência de te/você variam intensamente a depender do verbo utilizado na oração matriz, mostrando que não há uma tendência geral para a construção em si. Com base nesse resultado, podemos inferir que os traços semânticos de cada predicador verbal parecem influenciar a variante de $2 S G$ que preenche a posição de OD.

Correlacionando os resultados do experimento (efeito do contexto de contraste) com os da análise de corpus (efeito da construção de "sujeito acusativo"), Schwenter et al. (2018) observam que o aspecto em comum está na referência disjunta do pronome OD de 2SG. Nas construções de sujeito acusativo, o sujeito da oração matriz é obrigatoriamente distinto do sujeito da oração encaixada. Sendo assim, nas palavras dos autores, "dado que os contextos contrastivos com ODs [...] também têm necessariamente referência disjunta, isso representa um claro paralelo entre contextos de sujeito acusativo em que você é preferido e contextos contrastivos [...]" (SCHWENTER et al., 2018, p. 282).

Em síntese, vimos nesta seção que (i) a variação atual entre te e você na posição de objeto direto é, historicamente, um desdobramento do processo de gramaticalização e difusão da forma você no sistema pronominal do português, que, embora tenha principiado na posição de sujeito, tem afetado outros contextos morfossintáticos; (ii) os estudos diacrônicos mostram que, mesmo após a difusão de você no PB, a forma átona te persiste no contexto de OD, registrando, em peças teatrais e cartas pessoais, índices percentuais superiores aos de você; (iii) os estudos sincrônicos, baseados em dados de uso e de percepção, apontam que a baixa frequência de ocorrência de você não se deve a um estigma ou uma avaliação social negativa, mas sim a fatores discursivo-pragmáticos (contextos de contraste) e estruturais (configuração sintática da sentença).

Pautando-nos nesses resultados, justificamos, então, o recorte desta investigação, que objetiva explorar a variação te/você em uma construção específica. Entendemos que as "orações complexas", a que Pimienta (2013) se refere, e as "construções com sujeito acusativo", mencionadas por Schwenter et al. (2018), correspondem às conhecidas construções causativas, amplamente investigadas no português e em outras línguas. Adotaremos, neste artigo, a terminologia "construção causativa" para nos referirmos a esse tipo de estrutura. Na próxima seção, trataremos dessa construção, descrevendo e caracterizando os aspectos que serão relevantes para o experimento que elaboramos. 


\section{Caracterizando as construções causativas}

O campo de investigação linguística acerca das construções causativas é vastíssimo. Há uma generosa bibliografia disponível sobre o tema, que aborda diferentes aspectos dessas construções, a partir de perspectivas teóricas distintas. Evidentemente, seria impossível de contemplar, ainda que de forma sumária, toda a literatura existente neste artigo. Sendo assim, apresentamos, nesta seção, uma caracterização geral das causativas em português, enfatizando, intencionalmente, os seus aspectos semânticos, visto que eles são importantes para compreender as hipóteses formuladas neste estudo bem como as decisões metodológicas tomadas na elaboração do experimento de escolha induzida.

Ao explorar as construções causativas analíticas do português e do espanhol, Soares da Silva (2004, p. 581) as descreve como "estruturas de dois verbos (tipicamente) nas quais um expressa o predicado causal (ou evento causante) e o outro o predicado de efeito (ou evento causado)". Segundo o mesmo autor, o predicado causal é responsável por exprimir apenas a noção semântica de causa ou outras noções semanticamente relacionadas à causa, tais como manipulação, permissão e possibilidade. Desse modo, o verbo do predicado causal não veicula nenhum conteúdo lexical específico e é conceitualmente dependente do predicado de efeito. Em (05-07), temos alguns exemplos de construções causativas do português:

(05) O João fez a Maria sair.

(06) O João deixou a Maria sair.

(07) O João mandou a Maria sair.

Segundo Soares da Silva (2004), os verbos "fazer", "deixar" e "mandar" constituem o predicado causal ou evento causante, na oração matriz, e estão estreitamente relacionados ao evento expresso pela oração subordinada com o verbo "sair". Em (05), o sujeito "João" realiza alguma ação que se converte na causa do evento presente na subordinada. Em (06) e (07), a noção de causa é inferida a partir da semântica de permissão e de ordem presentes, respectivamente, nos verbos "deixar" " "mandar". Nos três exemplos, o fato de Maria ter saído é um efeito ou uma consequência do que está expresso na oração matriz.

Soares da Silva (2004) apresenta, ainda, uma detalhada caracterização acerca das causativas, baseada nos significados por elas veiculados. $\mathrm{O}$ autor argumenta que a grande complexidade gramatical dessas estruturas pode ser explicada menos por fatores puramente formais do que por fatores conceituais e semânticos. Para tanto, ele recorre ao trabalho de Talmy (2000), que propôs uma generalização para a noção linguística tradicional de "causativo". Segundo essa proposta, as construções causativas envolvem, tipicamente, uma relação de oposição entre duas entidades ("dinâmica de forças"): a entidade agonista, que exerce a força e corresponde ao causado, e a entidade antagonista, que exerce uma contraforça e corresponde 
ao causante. Soares da Silva (2004) apresenta, então, as quatro dimensões em que se baseia o sistema de padrões de dinâmica de forças elaboradas por Talmy:

a. tendência intrínseca de força do Agonista: movimento ou ação vs. repouso ou inércia;

b. mudança temporal: oposição entre forças mutáveis (início/fim da influência) vs. oposição de forças estáveis (continuação/não ocorrência da influência);

c. influência do Antagonista: o estado resultante do Agonista é o oposto de sua tendência intrínseca em 'causar', enquanto é o mesmo em 'deixar';

d. entidade mais forte: Antagonista vs. Agonista.

A fim de compreender essas dimensões envolvidas no sistema de dinâmica de forças, analisemos os exemplos (05) e (06), repetidos em (08-09), segundo o modelo proposto por Talmy (2000) e adotado por Soares da Silva (2004):

(08) João fez a Maria sair.

(09) João deixou a Maria sair.

A diferença fundamental entre os causativos "fazer" e "deixar" se torna evidente no âmbito da dinâmica de forças. Com "fazer", o Antagonista ("João") aplica uma força (física ou não) contra a tendência intrínseca do Agonista "Maria" (no exemplo, não sair), ao passo que, com "deixar", o Antagonista se abstém ou desiste de exercer uma força que poderia se opor à tendência do Agonista (ou seja, não permitir, proibir que a Maria saísse). Por isso, o resultado da interação de forças para o Agonista é o oposto ao de sua tendência intrínseca em "fazer", mas é o mesmo que em "deixar". Essas dimensões da dinâmica de forças serão relevantes para a formulação da hipótese a ser verificada nesta pesquisa, pois, como vamos expor mais adiante, acreditamos que propriedades semânticas relacionadas aos pronomes te e você interagem com propriedades semânticas das construções causativas, principalmente aquelas relacionadas ao Agonista e ao evento causado.

O verbo "fazer", em português (assim como seus correspondentes em outras línguas) seria, no entendimento de Soares da Silva (2004), o protótipo da construção causativa. Primeiramente, porque ele perfila uma noção de causação mais direta, sem outras noções combinadas (como as de permissão em "deixar", ou de ordem em "mandar"). Além disso, apresenta um campo mais extenso de aplicação semântica, funcionando como verbo de criação, causação física e manipulação interpessoal. Pode expressar, ainda, diferentes graus de força coercitiva e mesmo um sentido não intencional de causar. Segundo o mesmo autor, "fazer" também é o verbo que tem um campo mais amplo de construções gramaticais causativas.

O autor descreve quatro construções causativas do português: as com complemento infinitivo, com complemento finito, as causativas-reflexivas e as causativas predicativas/resultativas. No experimento deste estudo, exploramos a primeira delas, ou seja, as causativas 
com complemento infinitivo, razão pela qual daremos atenção especial às considerações de Soares da Silva (2004) acerca delas. O autor afirma que, em português, as causativas infinitivas podem ocorrer por meio de três estruturas distintas: Verbo-Sujeito-Verbo (VSV, em (10)), Verbo-Objeto-Verbo (VOV, em (11)) e Verbo-Verbo (VV, em (12)):

(10) A Maria fez os miúdos lerem esse livro.

(11) A Maria fez os miúdos ler esse livro.

(12) A Maria fez ler esse livro aos miúdos.

Soares da Silva (2004, p. 589) chama a atenção para as diferenças na marcação de caso do sujeito lógico do infinitivo: "a não alteração de marcação de caso dá origem à construção VSV [...], enquanto VOV [...] resulta da sua codificação como acusativo, ou objeto direto, do verbo principal". Nos exemplos, essa diferença de marcação casual pode ser percebida pela flexão do verbo "ler". Em (10), este verbo traz a desinência número-pessoal de $3^{a}$ pessoa do plural, o que significa que o constituinte "os miúdos" é marcado com o caso nominativo. Já em (11), o verbo "ler" não concorda em número-pessoa com o constituinte "os miúdos", o que indica que o constituinte "os miúdos" é marcado com o caso acusativo e funciona como objeto direto do verbo da oração matriz "fazer". Por fim, no exemplo (12), os verbos da oração matriz e da subordinada estão integrados ("fazer", nesse caso, funciona como um auxiliar de "ler") e o constituinte "os miúdos" é marcado com o caso dativo, indicado pela presença da preposição "a".

O autor salienta, entretanto, a importância de considerarmos os aspectos semânticos das causativas analíticas, uma vez que os aspectos formais não dão conta, por si só, da complexidade gramatical dessas construções. Segundo ele, "as construções causativas perfilam [...] o input de energia ou a força instigadora (codificada no sujeito principal ou causante) responsável pela ocorrência do evento complemento [...]" (SOARES DA SILVA, 2004, p. 590). Dessa maneira,

[...] o fator determinante da escolha de uma construção particular tem a ver essencialmente com qual é a entidade do evento complemento que se vê como inicialmente destacável [...] - ou o evento como um todo, ou o participante principal nesse evento (o sujeito lógico do infinitivo) (SOARES DA SILVA, 2004, p. 590).

Seguindo essa linha argumentativa, o autor afirma que é a (in)capacidade de interpretar o sujeito lógico do infinitivo como a fonte de energia do evento causado que motiva a seleção do tipo de causativa. Por esse raciocínio, nas causativas do tipo VSV, o sujeito lógico é considerado uma fonte de energia para realizar o evento causado, fato que explica uma maior autonomia da oração subordinada e do seu sujeito em relação ao predicado causal. Já nas causativas do tipo VOV, essa autonomia é menor já que o sujeito lógico seria uma fonte de 
energia também menor para realizar o evento causado. Isso explicaria, pois, a sua codificação como objeto do predicado causal.

Como, então, analisar essa capacidade de o sujeito lógico ser a "fonte de energia" do evento causado? Soares da Silva (2004) afirma que fatores mais específicos influenciam nessa interpretação. Dentre os listados pelo autor, destacamos as propriedades semânticas do verbo da oração subordinada e seu sujeito. Acreditamos que a agentividade do verbo da oração subordinada possa ser um parâmetro pertinente, visto que predicadores que expressam eventos mais agentivos, tais como "beber" e "limpar", envolvem necessariamente um sujeito agente, com controle e/ou volição da ação expressa pelo verbo. Assim, esse predicado causado constituirá um evento mais autônomo em relação ao predicado causal. Em contrapartida, predicadores como "sonhar" e "ouvir" envolvem um sujeito experienciador, menos agentivo, com menor (ou mesmo sem) controle e/ou volição do evento expresso pelo verbo. Nesse sentido, predicados causados com verbos menos agentivos instauram eventos menos autônomos em relação ao evento causante do predicado causal.

Feitos esses apontamentos teóricos acerca das construções causativas analíticas infinitivas e as possíveis correlações semânticas existentes entre elas e as variantes de 2SG te e você, trazemos, na próxima seção, a descrição do experimento de escolha induzida, elaborado para testar as hipóteses postuladas nos parágrafos anteriores.

\section{A tarefa de ESCOlHa INDUZIDA}

A fim de analisar se as construções causativas constituem uma variável linguística relevante na variação entre os pronomes acusativos te e você, recorremos ao experimento linguístico conhecido como tarefa de escolha induzida (do inglês, forced-choice task). Nesse experimento, são apresentados dois ou mais estímulos linguísticos (palavras, sintagmas ou sentenças) aos participantes e eles devem escolher aquele que julgam ser o mais aceitável, mais natural ou mais próximo do que eles acreditam que usariam. Método bastante utilizado nas pesquisas da área da psicolinguística, a tarefa de escolha induzida costuma ser projetada, segundo Schütze e Sprouse (2013, p. 31-32, grifo do original), "para comparar qualitativamente duas ou mais condições e responder diretamente à questão qualitativa existe alguma diferença entre essas condições?”.

As principais vantagens em adotar essa tarefa experimental são: a possibilidade de aplicação a distância, algo que se tornou uma necessidade durante o distanciamento social decorrente da pandemia do Sars-Cov-2, iniciada no final de 2019; a possibilidade de obtenção de um quantitativo razoável de participantes em um breve período de tempo, fato diretamente relacionado à aplicabilidade pela internet; a facilidade de execução da tarefa pelo participante; a confrontação direta entre as condições experimentais, algo que não ocorre com outros tipos 
de experimento (como os julgamentos de aceitabilidade com escala numérica, por exemplo); um alto poder estatístico para detectar diferenças entre as condições.

Por outro lado, é preciso pontuar também algumas limitações metodológicas. Primeiramente, a aplicação a distância reduz a supervisão do pesquisador acerca das circunstâncias em que o experimento foi realizado e, com isso, outros fatores podem eventualmente interferir nas respostas dos participantes (por exemplo, a presença de ruídos no ambiente que afetem a concentração, a consulta a outros indivíduos, pausas durante a execução da tarefa etc.). Esses fatores podem acentuar outro aspecto desse tipo de experimento: a variabilidade nas respostas dos participantes. Além disso, a tarefa de escolha induzida pode sinalizar se há diferenças de percepção entre as condições experimentais, porém não permite mensurar o tamanho dessa diferença (algo possível em um julgamento com escalas).

Feitas as considerações gerais acerca do método, passemos à descrição do projeto experimental desenvolvido para a análise dos pronomes te e você em construções causativas.

\section{DESENHO EXPERIMENTAL}

Adotamos um desenho experimental do tipo $2 \times 2$, no qual controlamos duas variáveis independentes: a variável tipo de pronome, com dois níveis (te ou você), e a variável agentividade do predicado de efeito, também com dois níveis (predicado mais agentivo e predicado menos agentivo). Desse modo, o experimento continha quatro condições experimentais: (i) Pronome te + predicado mais agentivo; (ii) Pronome te + predicado menos agentivo; (iii) Pronome você + predicado mais agentivo; (iv) Pronome você + predicado menos agentivo. Como variável dependente, adotamos o índice de escolha dos pronomes. Em (13) e (14), apresentamos dois pares de enunciados experimentais utilizados:

a. Bianca te fez jogar baralho.

b. Bianca fez você jogar baralho.

(14)

a. José te fez sonhar com o prêmio.

b. José fez você sonhar com o prêmio.

\section{MATERIAIS}

Elaboramos oito enunciados experimentais, divididos segundo a variável agentividade do predicado de efeito: havia quatro estímulos contendo predicados de efeito mais agentivos ("jogar", "beber", "limpar" e "dividir") e mais outros quatro, contendo predicados de efeito 
menos agentivos ("pensar", "ouvir", "sonhar" e "ver"). Organizamos os enunciados em dois formulários eletrônicos, cada qual com quatro itens experimentais e oito itens distratores. Adotamos uma configuração entre sujeitos (between-subjects), segundo a qual os participantes que responderam o formulário 1 só visualizaram frases com predicado de efeito mais agentivo, enquanto os participantes que responderam o formulário 2 só visualizaram frases com predicado de efeito menos agentivo. Quanto à variável tipo de pronome, todos os participantes foram expostos a enunciados com te e com você, uma vez que estes apareciam nos pares de opções a serem escolhidas.

Os enunciados experimentais consistiam em um minidiálogo. Na primeira parte, havia sempre uma sentença com o verbo dizer, do tipo $X$ disse para $Y$, em que $X$ e $Y$ eram nomes próprios. A fala simulada de $\mathrm{X}$ aparecia nas alternativas a serem escolhidas pelo participante: uma sentença contendo um sujeito simples (também nome próprio), a construção causativa (sempre com o verbo fazer na posição do predicado causal) e os pronomes de segunda pessoa do singular em análise, um em cada alternativa. Na figura 2, temos o exemplo de um dos enunciados construídos para o nosso experimento:

Figura 2 - Exemplo de item experimental no formulário eletrônico

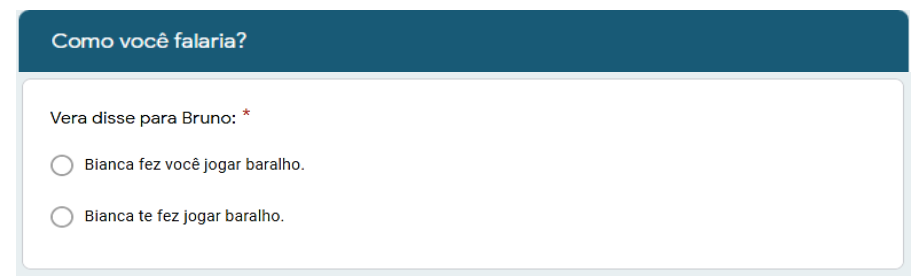

Fonte: elaboração própria

Organizamos os enunciados experimentais e distratores com o auxílio do aplicativo de gerenciamento de pesquisas Google Forms. A partir desse aplicativo, pudemos gerar um link para os formulários e compartilhá-los com os possíveis participantes através das redes sociais e do comunicador instantâneo WhatsApp. Os enunciados foram apresentados de maneira semialeatória, divididos em quatro seções: em cada seção, os participantes eram expostos a dois enunciados distratores e apenas um experimental; o enunciado experimental nunca era o primeiro da sequência. Reproduzimos, na figura 3, o modo como os participantes do formulário 1 viam o primeiro conjunto de enunciados: 
A PERCEPÇÃO DOS PRONOMES DE SEGUNDA PESSOA DO SINGULAR EM CONSTRUÇÕES CAUSATIVAS: UM ESTUDO EXPERIMENTAL

Figura 3 - Exemplo da primeira seção do experimento no Google Forms (formulário 1)

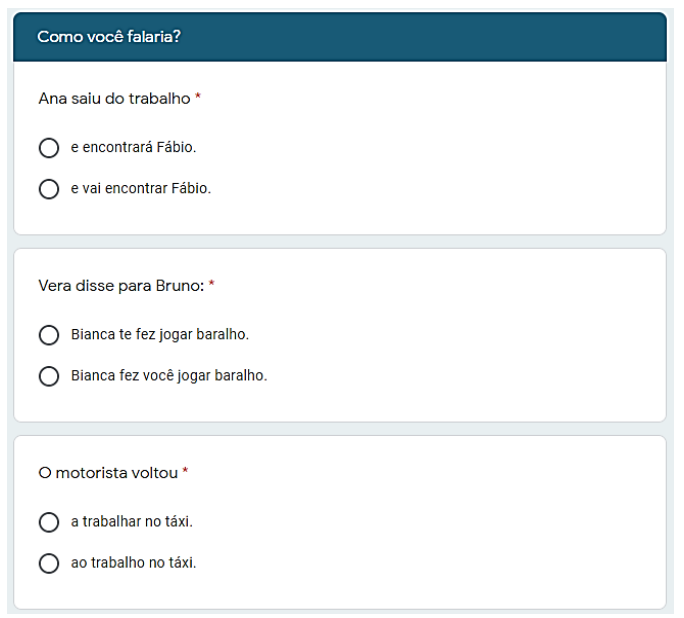

Fonte: elaboração própria

\section{Participantes}

Ao todo, 78 voluntários participaram do experimento (39 responderam o formulário 1 e os outros 39, o formulário 2). Na seção final do experimento, os participantes informaram o sexo, a faixa etária, o nível de escolaridade e a naturalidade. A partir desses dados, verificamos o seguinte perfil dos participantes: quanto ao sexo, 37 eram do sexo masculino e 41, do sexo feminino; quanto à faixa etária, 69 tinham entre 15 e 35 anos de idade e 9, entre 36 e 55 anos; quanto à escolaridade, 69 declararam ter ensino superior (completo ou em andamento) e 9, ensino médio; quanto à naturalidade, todos declararam ser naturais do Rio de Janeiro e sempre viveram na mesma cidade. A participação foi totalmente voluntária e as respostas eram registradas anonimamente, sem gerar qualquer informação mais específica quanto à identidade dos participantes (nome completo ou preenchimento de e-mail obrigatório, por exemplo). Os links dos formulários ficaram ativos (isto é, disponíveis para o recebimento de respostas) entre os dias 5 e 10 de março de 2021.

\section{PROCEDIMENTO}

Como já mencionamos anteriormente, todo o procedimento de montagem, divulgação e aplicação do experimento foi efetuado remotamente, através da internet. Os indivíduos que tinham interesse em participar da pesquisa acessavam o formulário através do link divulgado nas redes sociais e em grupos do WhatsApp. Clicando no link, eram direcionados para a página inicial do experimento, na qual havia as orientações gerais e um termo de concordância em 
responder voluntariamente o formulário. Respondendo positivamente ao termo, os participantes passavam, então, para as telas com os minidiálogos.

Nas quatro telas seguintes, o participante visualizava os itens da tarefa de escolha induzida, sendo apresentados sempre dois minidiálogos distratores e um minidiálogo experimental (cf. figura 3). Para avançar, era preciso selecionar obrigatoriamente uma das opções apresentadas em cada item. Na última tela do formulário, o participante devia informar o sexo, a faixa etária e o grau de escolaridade. Por fim, era preciso clicar na opção "enviar" e as respostas eram registradas automaticamente pelo Google Forms. A execução da tarefa durava, em média, cinco minutos.

\section{HiPÓTESES E PREVISÕES}

Nesta investigação, pretendemos pôr à prova duas hipóteses. A primeira, proposta por Schwenter et al. (2018), postula que a expressão variável dos pronomes acusativos de segunda pessoa do singular é sensível ao tipo de construção morfossintática em que esses pronomes ocorrem; mais especificamente, os referidos autores afirmam que a variante acusativa você tem seu uso favorecido no interior de construções causativas, em detrimento da variante te, mais utilizada em sentenças transitivas básicas. A segunda hipótese, pensada no âmbito desta pesquisa e relacionada com a hipótese de Schwenter et al. (2018), presume que aspectos semânticos vinculados às construções causativas também condicionam a variação entre te e você; acreditamos que a semântica do verbo do predicado do evento causado influencia a escolha/o uso dos pronomes, sendo a variante você favorecida por verbos mais agentivos.

Dessas hipóteses, derivam as seguintes previsões experimentais: (i) no experimento como um todo, os participantes escolherão mais frequentemente as opções com a variante você, uma vez que todas as sentenças apresentadas contêm construções causativas; (ii) a escolha pelas opções com a variante você será significativamente mais frequente quando, no predicado de evento causado, houver um verbo mais agentivo ("jogar", "beber", "limpar" e "dividir"); (iii) em contrapartida, a escolha pelas opções com a variante te será mais frequente quando houver um verbo menos agentivo ("pensar", "ouvir", "sonhar" e "ver") no predicado de evento causado.

$\mathrm{Na}$ sequência, reportamos os resultados preliminares obtidos com a aplicação dos formulários eletrônicos.

\section{RESULTADOS PRELIMINARES}

Agrupamos as respostas dos participantes dos formulários em uma planilha e, em seguida, realizamos as análises de estatística descritiva (no Microsoft Excel) e inferencial (no programa Action Stat Pro). Apresentamos, primeiramente, os resultados gerais, a fim de verificar 
se as construções causativas das frases experimentais favoreceram a escolha de uma variante de 2SG em detrimento de outra. A figura 4 traz uma síntese dos resultados globais:

Figura 4-Frequência geral de escolha das frases com os pronomes de 2SG pelos participantes

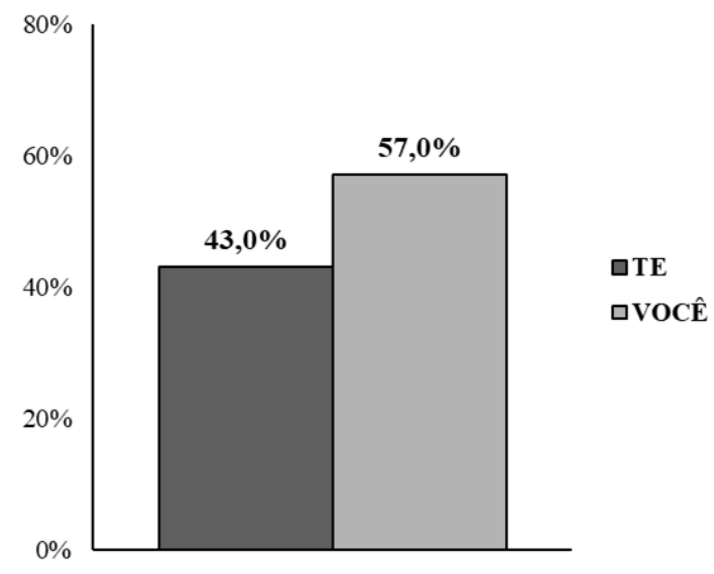

Fonte: elaboração própria

$\mathrm{Na}$ figura 4, visualizamos os índices percentuais de escolha das frases no formulário segundo o tipo de pronome (te ou você). Calculamos os valores percentuais a partir das respostas fornecidas pelos 78 participantes para os enunciados experimentais. Como podemos perceber, as opções que traziam o pronome você foram, em termos gerais, as mais escolhidas pelos sujeitos, correspondendo a uma frequência de 57\% do total (isto é, 178 das 312 respostas registradas). Já as opções com o pronome te foram escolhidas em $43 \%$ das respostas (ou seja, 134 das 312 registradas).

Em termos descritivos, esses índices percentuais revelam que as escolhas induzidas dos participantes refletem a expressão variável do objeto direto de $2 \mathrm{SG}$, com o predomínio da variante você sobre te no contexto das construções causativas. Com o intuito de verificar se essa diferença percentual observada no gráfico é estatisticamente relevante, aplicamos um teste de qui-quadrado aos dados experimentais. $O$ resultado do teste apontou que tal diferença é significativa (te/você: $\chi^{2}=6,20, p<0,05$ ).

Ao considerarmos as escolhas das frases com as variantes pronominais de 2SG em relação à semântica do verbo do predicado do evento causado, temos os seguintes índices percentuais, representados na figura 5: 
Figura 5 - Frequência de escolha das frases com os pronomes de 2SG em relação à agentividade do predicado do evento causado

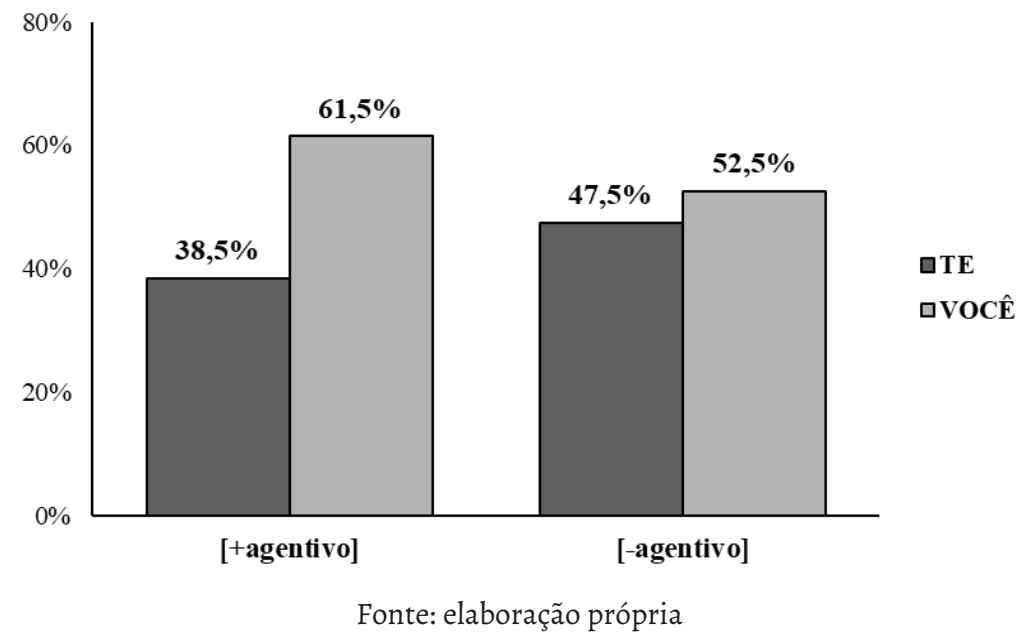

Primeiramente, podemos notar que a distribuição variável observada na figura 4 também aparece nessa análise quanto à semântica do verbo, com os índices relativos aos enunciados que continham o pronome você sendo mais altos do que aqueles registrados para os enunciados que apresentavam o pronome te. Há, no entanto, uma diferença quantitativa na predominância de você, que se relaciona à semântica do verbo: dentre os enunciados com verbos semanticamente mais agentivos, o índice de escolha das frases que traziam o pronome vocêe de $61,5 \%$ (96 de 156 respostas), contra os 38,5\% de escolha das frases com o pronome te (60 de 156 respostas); já nos enunciados que apresentavam verbos semanticamente menos agentivos, a distância entre os índices de escolha das frases com você e te diminui, sendo 52,5\% para o primeiro (82 de 156 respostas) e 47,5\% para o último (74 de 156 respostas).

Ao analisarmos estatisticamente os resultados da figura 5, por meio do teste de qui-quadrado, encontramos uma diferença significativa em relação aos índices de escolha das frases com você e com te para os enunciados que envolviam predicados de evento causado mais agentivos (te/você [+agentivo]: $\chi^{2}=8,30, \mathrm{p}<0,01$ ). Contudo, a diferença registrada entre os índices de escolha para os enunciados em que os predicados de evento causado eram menos agentivos não foi significativa pelo teste estatístico aplicado (te/você [-agentivo]: $\left.\chi^{2}=0,41, p=0,52\right)$.

\section{DISCUSSÃo}

Em linhas gerais, podemos dizer que os resultados preliminares da nossa pesquisa, obtidos a partir da aplicação da tarefa de escolha induzida, vão na direção das hipóteses investigadas neste estudo. Conforme ilustra o gráfico da figura 4, os índices percentuais de escolha 
dos participantes quanto ao tipo de pronome evidenciam uma preferência pela variante você (57\%) em detrimento da variante te (43\%). Essa preferência, seguindo a hipótese de Schwenter et al. (2018), parece estar intimamente relacionada ao fato de as formas pronominais terem sido apresentadas, em todos os enunciados experimentais, no interior de construções causativas. Cabe lembrar que, nos trabalhos mencionados em seções anteriores, que incluíam também sentenças transitivas básicas, a distribuição entre as variantes era inversa, com predomínio da variante te (p. ex., cf. tabela 3, com os dados de uso de Pimienta (2013)). O resultado geral do experimento reflete, portanto, um condicionamento estrutural sobre a variação das formas pronominais de $2 \mathrm{SG}$ em função de objeto direto, em favor da variante você.

Além disso, apesar de as previsões não terem sido totalmente confirmadas pelos resultados, encontramos, no gráfico da figura 5 , evidências positivas na direção da hipótese levantada em nossa pesquisa: a agentividade do predicado do evento causado parece ter influenciado as escolhas dos participantes. Como vimos, as frases que traziam a variante você foram significativamente mais escolhidas $(61,5 \%)$ do que as que traziam a variante te $(38,5 \%)$ quando os verbos do predicado do evento causado eram semanticamente mais agentivos (no experimento, utilizamos os verbos "jogar", "beber", "limpar" e "dividir"). Dentre os enunciados experimentais que envolviam verbos semanticamente menos agentivos, as opções com o pronome você também foram as mais escolhidas (52,5\%), o que contraria a nossa previsão; entretanto, dois aspectos são dignos de nota: (i) o índice percentual de escolha das frases com te foi mais alto no contexto dos verbos menos agentivos (47,5\%) em comparação aos mais agentivos (38,5\%); e (ii) a análise estatística, a partir do teste de qui-quadrado, revelou que a diferença entre os índices de escolha de te e você, no âmbito dos verbos menos agentivos, não foi significativa.

Desse modo, parece possível dizer que, para além do condicionamento estrutural que favorece a variante você, há, ainda, a atuação de um fator semântico, diretamente relacionado ao predicado do evento causado das construções causativas: a agentividade do verbo desse predicado. A questão que se coloca, a partir dos resultados, é: por que vocêe a forma favorecida nessa combinação "estrutura causativa + predicado do evento causado mais agentivo"?

Para responder essa questão, acreditamos que os aspectos históricos e funcionais atinentes às duas formas pronominais em foco são imprescindíveis. Como já mencionamos anteriormente, o pronome te é um resquício do sistema de flexão casual do latim, língua na qual era utilizado para marcar o caso acusativo. Em português, essa forma é utilizada exclusivamente como complemento verbal, principalmente como objeto direto. ${ }^{5} \mathrm{Em}$ termos funcionais, sabemos que, prototipicamente, as entidades que exercem a função de objeto direto são afetadas/efetuadas pela ação verbal, tendo, na semântica da frase, o papel temático correspondente ao paciente da ação (LUCENA, 2011).

\footnotetext{
${ }^{5}$ A forma te também pode funcionar como objeto indireto (dativo) em frases como "eu te dei o livro" e "eu te disse a verdade". Segundo algumas gramáticas históricas, essa coincidência é um caso de homonímia, provocada por alterações morfofonológicas na forma original de dativo, ainda no latim vulgar (cf. CAMARA Jr., 1985; williams, 1994).
} 
Por outro lado, o pronome você é uma forma de 2SG que emerge ao longo da história da língua portuguesa e, dentre outros aspectos, não é morfologicamente especificada para nenhuma função sintática (sabemos se essa forma exerce função de sujeito ou de objeto dentro da frase a partir de outros fatores, como, por exemplo, a posição sintática em relação ao verbo). As pesquisas diacrônicas mostram, todavia, que você teria se implementado no sistema pronominal do português através da posição de sujeito da oração (RUMEU, 2008; MACHADO, 2011), contexto sintático que, até os dias atuais, mais favorece a ocorrência desse pronome (CITAR). Novamente, em termos funcionais, temos que, prototipicamente, as entidades que exercem função de sujeito costumam receber o papel temático de agente, podendo apresentar, ainda, controle e/ou volição acerca da ação expressa pelo verbo (LUCENA, 2011).

Em síntese, a explicação que, por ora, oferecemos para os resultados iniciais da pesquisa está ancorada nos aspectos históricos e funcionais mencionados. Argumentamos, portanto, que a semântica [+agentiva] dos verbos da oração completiva, associada à configuração das construções causativas em análise, é responsável pelas escolhas significativamente mais frequentes das frases com o pronome você pelos participantes do experimento. Tendo em vista que, nas causativas, o constituinte que funciona como OD do verbo da oração matriz atua, simultaneamente, como o sujeito lógico da oração completiva (que contém o predicado do evento causado), você é a variante de 2SG mais compatível para esse contexto, já que traz no seu "DNA" propriedades formais e semânticas que a licenciam tanto como sujeito quanto como objeto direto no português.

\section{Considerações FinaIS}

Procuramos dialogar, neste trabalho, com os estudos sobre o sistema pronominal do PB (sobretudo com aqueles que tratam da expressão variável da segunda pessoa do singular), ao explorar a influência de fatores estruturais e semânticos no condicionamento da variação entre as formas te e você. Adotando uma metodologia experimental (ainda pouco explorada nas análises variacionistas brasileiras, em comparação aos métodos observacionais), nosso objeto foi verificar se as construções causativas e a agentividade de verbos relacionados a essas construções influenciariam o julgamento dos participantes do experimento de escolha induzida. Conforme procuramos explicitar nas seções de resultados e discussão, nossos resultados iniciais vão na direção das hipóteses postas à prova.

Trata-se, no entanto, de um primeiro passo dentro de uma agenda de pesquisa a que pretendemos dar continuidade, com investigações futuras. Como destacamos na seção de metodologia, exploramos, no experimento elaborado, apenas um tipo de construção causativa, utilizando, nas condições experimentais, sempre o mesmo verbo causativo: "fazer", apontado por Soares da Silva (2004) como o prototípico. Evidentemente, será necessário, 
nos próximos passos, contemplar nas análises outros verbos causativos (tais como "mandar e "deixar"), o que, além de expandir a investigação, também possibilitará a comparação entre os resultados obtidos para cada verbo causativo. Há, ainda, as construções que envolvem os verbos perceptivos (como "ver" "ouvir"), que apresentam uma configuração bastante similar à das causativas e que também podem conter os pronomes te e você (Ele te viu sair de casa / Ele viu você sair de casa).

Por fim, destacamos duas contribuições que, a nosso ver, esta análise pode trazer para os estudos sobre a expressão pronominal de $2 \mathrm{SG}$ em contexto de objeto direto. A primeira, de ordem explanatória, diz respeito à testagem de fatores que condicionariam a variação de objeto direto te/você, apontados por investigações precedentes (PIMIENTA, 2013; SCHWENTER et al., 2018). Embora venha sendo mais descrita nas pesquisas sociolinguísticas dos últimos anos, a variação de $2 S G$ fora da posição de sujeito da oração ainda conta com poucas análises que explorem as variáveis que condicionam o uso/a escolha das variantes, fato que justifica a presente pesquisa, que buscou analisar dois fatores que condicionam a variação na posição de objeto direto de 2SG. A segunda, de ordem metodológica, refere-se à utilização da metodologia experimental para o estudo de fenômenos de variação, tradicional e majoritariamente investigados a partir de corpora linguísticos. Nesse sentido, esperamos que o nosso trabalho sirva de estímulo para que cada vez mais estudiosos da variação e da mudança linguística no português adotem a metodologia experimental e, com isso, possam não só enriquecer como também integrar os estudos baseados no uso aos estudos de percepção linguística.

\section{REFERÊNCIAS}

CAMARA JR., J. M. História e Estrutura da Língua Portuguesa. 4. ed. Rio de Janeiro: Padrão, 1985. CINTRA, Luís F. Lindley. Sobre "Formas de Tratamento" na língua portuguesa. Lisboa: Livros Horizonte/Coleção Horizonte 18. 1972.

FARACO, Carlos Alberto. O tratamento Você em português: uma abordagem histórica. Fragmenta. Curitiba: No 13, Editora da UFPR, p. 51-82. 1996.

LOPES, C. R. dos S. et al. A reorganização no sistema pronominal de 2a. pessoa na história do português brasileiro: outras relações gramaticais. In: LOPES, C. R. dos S. (Coord.). Mudança sintática das classes de palavra: perspectiva funcionalista; história do português brasileiro. São Paulo: Contexto, 2018. p. 142-185.

LOPES, C. R. dos S.; CAVALCANTE, S. A cronologia do voceamento no português brasileiro: expansão de você-sujeito e retenção do clítico-te. Revista Lingüistica, Madrid, v.25, p.30-65, 2011. Disponível em: http://www.linguisticalfal.org/25_linguistica_030_065.pdf. Acesso em: 27 ago. 2021. 
LOPES, C. R. dos S.; DUARTE, M. E. L. De Vossa Mercê a Você: análise da pronominalização de nominais em peças brasileiras e portuguesas setecentistas e oitocentistas. In: Análise contrastiva de variedades do português: primeiros estudos. 1. ed. Rio de Janeiro: In-Fólio, 2003, v.I, p. 61-76.

LUCENA, N. L. de. Relação gramatical objeto direto: a interface entre sintaxe, semântica e pragmática. Letrônica, 4(1), 2011, p. 12-30. Disponível em: https://revistaseletronicas.pucrs. br/ojs/index.php/letronica/article/view/7876/6279. Acesso em: 22 jul. 2021.

MACHADO, A. C. M. As formas de tratamento no teatro brasileiro e português dos séculos XIX e XX. 2011. 237 f. Tese (Doutorado em Letras Vernáculas) - Faculdade de Letras, Universidade Federal do Rio de Janeiro, Rio de Janeiro, 2011.

PIMIENTA, P. C. S. La segunda persona de singular en el portugués de Rio de Janeiro: Variación en la relación gramatical de Objeto Directo. 2013. 169 f. Dissertação (Mestrado em Linguística Aplicada) - Centro Universitario de Ciencias Sociales y Humanidades, Universidad de Guadalajara, Guadalajara, 2013.

RUMEU, M. C. de B. A implementação do 'Você' no Português Brasileiro Oitocentista e Novecentista: Um estudo de painel. Rio de Janeiro: UFRJ/FL, 2008. Disponível em: http:// www.dominiopublico.gov.br/pesquisa/DetalheObraForm.do?select_action=\&co_obra=136959. Acesso em: 20 ago. 2021.

SCHÜTZE, C. T.; SPROUSE, J. Judgement data. In: PODESVA R.; DEVYANI; SHARMA (Ed.). Research methods in linguistics. New York: Cambridge University Press, 2013, p. 27-50.

SCHWENTER, S. A. et al. Experimental evidence for 2 SG direct object pronoun preferences in Brazilian Portuguese. In: Revista Linguística. Rio de Janeiro, v. 14, n.2, maio-ago. 2018, p. 259-290. Disponível em: https://revistas.ufrj.br/index.php/rl/article/view/17608/13074. Acesso em: 15 jun. 2021.

SOARES DA SILVA, A. Verbos y construcciones causativas analíticas en portugués y en español. In: HONRUBIA, J. L. C.; LLORCA, C. M. (Coords.). Estudios de Lingüística Universidad de Alicante. 10.14198/ELUA, 2004, p. 581-598.

SOUZA J. P. F. de. Mapeando a entrada do Você no quadro pronominal: análise de cartas familiares dos séculos XIX-XX. 2012. 148 f. Dissertação (Mestrado em Letras Vernáculas) Faculdade de Letras, Universidade Federal do Rio de Janeiro, Rio de Janeiro, 2012. Disponível em: https://laborhistorico.letras.ufrj.br/Mestrado/SouzaJPF.pdf. Acesso em: 25 ago. 2021.

SOUZA, C. D. de. Eu te amo, eu lhe adoro, eu quero você: a variação das formas de acusativo de $2^{a}$ pessoa em cartas pessoais (1880-1980). 2014. 156 f. Dissertação (Mestrado em Letras Vernáculas) - Faculdade de Letras, Universidade Federal do Rio de Janeiro, Rio de Janeiro, 2014. Disponível em: http://www.posvernaculas.letras.ufrj.br/images/Posvernaculas/3-mestrado/ dissertacoes/2014/3-SouzaCD.pdf. Acesso em: 15 jun. 2021. 
A PERCEPÇÃO DOS PRONOMES DE SEGUNDA PESSOA DO SINGULAR EM CONSTRUÇÕES CAUSATIVAS: UM ESTUDO EXPERIMENTAL

TALMY, L. Force dynamics in language and cognition. In: Talmy, L. Toward a Cognitive Semantics, v. I: Concept Structuring Systems. Cambridge, Mass: The MIT Press, 2000, p. 409-470.

WILLIAMS, E. B. Dolatim ao português: fonologia e morfologia históricas da língua portuguesa. Trad. Antônio Houaiss. 6. ed. Rio de Janeiro: Tempo Brasileiro, 1994.

Recebido para publicação em: 4 set. 2021. Aceito para publicação em: 8 out. 2021. 